\title{
Does iron-fortified chewing gum influence the biochemical profile of school-going
}

\section{children (6-10 yrs.)?}

\author{
Muhammad Azeema, Mian Kamran Sharif ${ }^{a}$, Faiz-Ul-Hassan Shah ${ }^{b}$, Maratab Ali ${ }^{a}$, Muhammad Amer Nazir ${ }^{c}$, \\ Muhammad Rizwan ${ }^{a}$, Syed Abdul Wadood ${ }^{\mathrm{a}}$ and Rebia Ejaz ${ }^{\mathrm{a}}$
}

${ }^{a}$ National Institute of Food Science E Technology, University of Agriculture, Faisalabad 38040, Pakistan; ${ }^{b}$ Department of Food Science and Technology, The Islamia University of Bahawalpur, Bahawalpur, Pakistan; 'Department of Pathology, BSLIII lab, DHQ Teaching Hospital, Dera Ghazi Khan, Pakistan; ${ }^{d}$ Department of Food and Nutrition, University of Home Economics, Lahore

*Corresponding Author: Mian Kamran Sharif, National Institute of Food Science \& Technology, University of Agriculture, Faisalabad 38040, Pakistan. Email: mks@uaf.edu.pk

Received: 14 February 2020; Accepted: 03 December 2020; Published: 01 February 2021

(C) 2021 Codon Publications

OPEN ACCESS (c)

PAPER

\begin{abstract}
Iron deficiency has become a common nutritional problem of developing countries, especially in children. This study approached to tackle the issue of iron deficiency by inexpensive fortified food such as chewing gums, which is commonly consumed by children. In this study, iron-fortified chewing gums were prepared by adding ferrous sulfate $\left(\mathrm{FeSO}_{4}\right)$ and sodium iron EDTA (NaFeEDTA) $30 \mathrm{mg} / 100 \mathrm{~g}$. An efficacy trial was conducted to determine the impact of iron-fortified chewing gums on the blood profile and iron status of school-going children $(\mathrm{n}=300)$. Results showed maximum increase in blood profile and iron status that is, serum ferritin (10.43\%), hemoglobin (3.22\%), hematocrit (3.42\%), red blood cells (3.05\%), mean cell volume (1.55\%), mean cell hemoglobin (5.43\%), total white blood cells count (9.09\%), and platelets count (4.40\%) as compared with control whereas decrease in mean cell hemoglobin concentration (1.90\%) and neutrophils (3.33\%) was also observed. The study concluded that $\mathrm{FeSO}_{4}$ and NaFeEDTA (1:1) fortification of chewing gums is an appropriate approach for mitigating iron deficiency among the target population.
\end{abstract}

Keywords: complete blood count (CBC), daily value (DV), ferrous sulfate $\left(\mathrm{FeSO}_{4}\right)$, iron deficiency anemia (IDA), sodium iron EDTA (NaFeEDTA)

\section{Introduction}

Iron (Fe) deficiency anemia (IDA) is known as a predominant nutritional deficiency worldwide. It has depicted substantial economic losses and health problems to distress a massive segment of global population (Petry et al., 2016). IDA causes maternal hemorrhage, reduced productivity, decreased school performance, and innumerable mortalities in vulnerable population. Nearly 700 to 800 million people worldwide are affected by the IDA, which severely distresses $60-70$ million people in developing countries. Approximately $65 \%$ of pregnant women in South Asia suffer from IDA (Siddiqui et al., 2007).

Numerous reports have revealed that $65-78 \%$ of children aged $<5$ years are suffering from IDA; their hemoglobin (Hb) levels were found below $11 \mathrm{~g} / \mathrm{dL}$ (Akhtar et al., 2013; Menon and Yoon, 2015). According to another report, the occurrence of anemia was estimated as $82.90 \%, 85 \%$, $83 \%$, and $78 \%$ among children, adolescent girls, pregnant, and lactating women, respectively (Akhtar et al., 2013). 
Survey of semi-urban areas of Abbottabad and Peshawar exhibited the occurrence of iron deficiency among children aged $<2$ years as $68 \%$ and $69 \%$, respectively (Idris and Anis-ur-Rehman, 2005). Similarly, in urban slums of Karachi, occurrence of IDA has been depicted as up to $61 \%(\mathrm{Hb}<11 \mathrm{~g} / \mathrm{dL})$ and low hematocrit $(\mathrm{PCV})(63.80 \%$ in children aged 6-60 months). The prevalence of anemia among rural-based pre-school children of Karachi has shown highly significant results (Molla and Khurshid, 1992). Likewise, according to another survey conducted in Pakistan, approximately $69 \%$ children aged $<2$ years, $40-50 \%$ of pre-school and primary school children, $39 \%$ of adolescents, $30 \%$ of adult females, and $54 \%$ of young girls were reported to be affected by IDA (Khor, 2005). In Pakistan, IDA has also been demonstrated as a severe health problem in pre-school children, followed by pregnant and nonpregnant women (World Health Organization [WHO], 2011).

The WHO has recommended four basic strategies to control and prevent IDA, which include increased iron intake, control of infection, supplementation, and food fortification (Prentice et al., 2017). A lot of iron fortification success stories have been reported in literature, that is, countries of the Middle East, Mongolia, Kyrgyz Republic, Kazakhstan, Tajikistan, Azerbaijan, North Africa, and Uzbekistan have successfully implemented iron fortification in wheat and corn flour (Mclean et al., 2008). In fortification of food, either voluntarily or mandatorily, in order to achieve optimum results and to avoid side effects, concentration of iron fortificants should be carefully monitored. Additionally, extensive research has to be practiced to preserve flavor, color, and appearance of food (Kuong et al., 2016). Predominant constraints for the success of any fortification depend upon the types and appropriate concentration of fortificants, fortified food, and viability of plans. Isotopic studies indicated that iron absorption from NaFeEDTA was possibly two to three times higher than the other form of iron used as a fortificant (Hurrell, 2002). Huo et al. (2002) investigated that NaFeEDTA-fortified soy sauce intervention within concentrations of 5 and $20 \mathrm{mg} F$ Fe/day significantly improved the iron status in children (aged 11-17 years). Davidsson et al. (2002) evaluated bioavailability of iron in foods based on corn tortillas and black bean paste fortified with ferrous sulfate $\left(\mathrm{FeSO}_{4}\right)$, ferrous fumarate, and $\mathrm{Na}-\mathrm{FeEDTA}$, and concluded that NaFeEDTA retains the higher geometric mean bioavailability (9.0\%) than $\mathrm{FeSO}_{4}$ (5.5\%). Bouhouch et al. (2016) investigated and concluded that the influence of wheat flour biscuits fortified with iron and EDTA resulted in improved iron status significantly, but failed to show any positive influence on cognitive scores. In another study, maize flour, fortified with iron such as NaFeEDTA at in high and low concentrations $(56$ and $28 \mathrm{mg} / \mathrm{kg}$ ) along with electrolyte iron (56 mg/kg) was fed to school children (aged 3-8 years) in Kenya. Its findings revealed that only high concentration of NaFeEDTA improved the iron status in children (Andang'o et al., 2007). Arcanjo et al.(2010) used $\mathrm{FeSO}_{4}^{-}$ fortified drinking water with different concentrations of $\mathrm{FeSO}_{4}(5,7.5$, and $10 \mathrm{mg} / \mathrm{L}$ ) for a period of four months, and suggested that $7.5 \mathrm{mg} / \mathrm{L}$ of $\mathrm{FeSO}_{4}$-fortified drinking water enhanced the hemoglobin level along with significant reduction in anemia. Moretti et al. (2006) advocated the influence of extruded rice fortified with ferric pyrophosphate in Indian school children and showed that IDA reduced from 15 to $30 \%$ within the group using iron-fortified meals whereas the control group indicated nonsignificant difference $(P>0.05)$. Indeed, bioavailability of iron relies on the composition of meals, and presence of enhancers and inhibitors during iron absorption (Davidsson et al., 2002). Besides selecting suitable vehicles during fortification, processing of food is also crucial. Traditionally, in many countries, cereal products are used as vehicles for fortification. Other vehicles include fish sauce, sugar, common salt, and cookies (Sari et al., 2001). However, chewing gums are selected because they are more preferred by children in every economic segment of population. Currently, $\mathrm{FeSO}_{4}$ and $\mathrm{NaFeEDTA}$ are being used to fortify food products. Presently, stability, acceptability, and bioavailability of iron compounds in the final product are critical issues and need to be explored to a greater extent.

The objective of the present study was to prepare the cheaper fortified chewing gums and to elucidate changes in proximate composition, minerals, and texture; its impact on the blood profile and iron status of school-going children was also explored.

\section{Materials and Methods}

\section{Materials}

Ingredients required for the preparation of chewing gums were procured from the local market. All reagents (analytical) were procured from Merck (Merck $\mathrm{KG}_{\mathrm{a}}$ A, Darmstadt, Germany) and Sigma-Aldrich (Sigma Aldrich, USA). All other chemicals and reagents used were of analytical grade.

\section{Preparation of iron-fortified chewing gums}

Water $(10 \mathrm{~kg})$ and glucose $(30 \mathrm{~kg})$ were mixed, followed by the addition of $50-\mathrm{kg}$ sucrose and $24 \mathrm{~kg}$ gums. The mixture was heated at $154^{\circ} \mathrm{C}$ followed by the removal of vacuum to get a better color, texture, and flavor. Furthermore, vacuum application decreased mixing to wrapping time. Other ingredients such as color $(0.9 \mathrm{~g})$, flavor $(4.5 \mathrm{~mL})$, black salt $(2.5 \mathrm{~g})$, and citric acid $(2.5 \mathrm{~g})$ 
were added per kilogram of the above mixture and mixed uniformly. Successively, after the approval of ethical committee, $\mathrm{FeSO}_{4}(30 \mathrm{mg})$ and NaFeEDTA (100 g) were added in 1:1 ratio. After cooling, the mixture was rolled into a sheet and passed through roller press to get chewing gums of uniform size (5 g). Wrapping was done through a central seal machine to remove air and to extend shelf life of the product.

\section{Proximate composition}

Chewing gum samples were analyzed on a dry weight basis for crude protein (Method No. 46-30), crude fat (Method No. 30-25), crude fiber (Method No. 32-10), ash (Method No. 08-01), and nitrogen-free extract (NFE) according to their respective procedures. Minerals' analysis was done using the procedure described by Azeem et al. (2019).

\section{Textural analysis}

Hardness of samples was measured using a texture analyzer (TA-XT2, Plus, Stable Microsystems, Surrey, UK) interfaced with a computer. To compare the hardness of chewing gums, 2-mm cylinder probe $(\mathrm{P} / 2)$ with a $5-\mathrm{kg}$ load was used. For data analysis, Texture Expert program, version 4.0.9.0, was used.

\section{Energy value}

Energy value of chewing gums was determined by taking $0.5 \mathrm{~g}$ of sample using Oxygen Bomb Calorimeter (C2000 Basic, IKA'-Werke GMBH \& Co., KG, Staufen, Germany) as described by Krishna and Ranjhan (1981).

\section{Sensory acceptability}

Sensory acceptability was assessed using a 9-point hedonic scale system, commencing from $1=$ dislike extremely up to $9=$ like extremely, for sensory attributes like color, flavor, mouthfeel, stickiness, texture, hardness, and overall acceptability by following the instructions of (Meilgaard et al., 1999).

\section{Efficacy trial}

Healthy school-going children (boys) aged 6-10 years, with a hemoglobin concentration of $<11 \mathrm{~g} / \mathrm{dL}$, from lowto moderate-income families were selected for efficacy study after the approval of the ethical committee of Allied Hospital, affiliated to the Department of Medicine (No. 09-0234), Punjab Medical College, Pakistan. An efficacy trial was carried out from 10 March 2016 to 15 April 2016 in two middle schools of district Jhang, Pakistan. Parents and children were invited in a seminar to introduce them the purpose, procedure, potential risks, and benefits of the study, and parents' written consent was taken. Complete enrollment and randomization procedure was explained. Parents of 318 children showed willingness to get enrolled in the study. An acceptability trial was conducted prior to efficacy studies to familiarize the children with sensory properties of the proposed iron-fortified chewing gums. Children were examined by a physician to determine whether they are healthy enough to be included in the study. Eighteen children were excluded, who were found diseased, infected, stunted, and malnourished. Finally, 300 healthy children, free from any chronic and acute disease, were stratified by computer-generated random numbers into four groups $\left(\mathrm{T}_{1}-\mathrm{T}_{4}\right)$ with 75 children in each group. Fortified chewing gums $(5 \mathrm{~g})$ were given during the recess time to each selected child for 45 days continuously. In case of absence of child from school, missed chewing gums were compensated by provision of one extra chewing gum on the following day with advice to consume at midnight. The consumption and distribution of chewing gums were monitored by the authors and teachers. The blood samples were collected at baseline and after 45 days of intervention by a welltrained phlebotomist in the presence of a medical doctor through venipuncture procedure. Each group consumed chewing gums according to the following pattern.

T1: Group of children served with chewing gums without fortificants (control group); T2: Group of children served with chewing gums fortified with $\mathrm{FeSO}_{4}(100 \%)$; T3: Group of children served with chewing gums fortified with $\mathrm{FeSO}_{4}(50 \%)$ and NaFeEDTA (50\%), and T4: Group of children served with chewing gums fortified with NaFeEDTA (100\%). $\mathrm{T}_{1}$ group was a placebo group. During the period of intervention, parents were advised to remain consistent with their children's dietary habits, constraining them from using any supplements. During pretrial, students complaining diarrhea were managed by decreasing the concentration of iron to the required level $(30 \mathrm{mg} / 100 \mathrm{~g})$. Since placebo group was considered as a control group, parents knew that their children were receiving chewing gums but were not aware whether chewing gums possessed iron or not.

\section{Complete blood count (CBC)}

Blood samples $(5 \mathrm{~mL})$ of each child were collected at the baseline and after 45 days of intervention through venipuncture procedure by a well-trained phlebotomist. Each 5 -mL blood sample was divided into two equal parts and transferred into an erythrocyte sedimentation rate (ESR) tube and a gel tube (anticoagulant-free tube) to collect serum. Immediately after sample collection, CBC was carried out in ESR tubes separately using a CBC analyzer (Sy-Bh192, Sunny Medical Equipment Limited., 
Guangzhou, China), which analyzed the following parameters: hemoglobin, hematocrit, red blood cells (RBCs), mean cell volume (MCV), mean cell hemoglobin $(\mathrm{MCH})$, mean cell hemoglobin concentration $(\mathrm{MCHC})$, total white blood cells count (TWBCC), neutrophils, platelets count (PLT), and erythrocyte sedimentation rate. Samples collected in gel tubes were centrifuged to isolate serum that was placed in refrigerator at $-20^{\circ} \mathrm{C}$ for further tests.

\section{Serum ferritin and iron}

Serum ferritin (SF) concentrations were measured according to the method described by Sari et al. (2001) within $1 \mathrm{~h}$ of blood collection by using the enzyme immunoassay method (IMx System; Abbott, Abbott Park, IL). Iron concentration was performed according to the method described by Schoorl et al. (2012) using semi-automatic clinical chemistry analyzer (YSTE 168, Guangzhou Yueshen Medical Equipment Co. Ltd., Guangzhou, China).

\section{Statistical analysis}

All samples were analyzed in triplicate, and the results were presented as mean \pm standard deviation. The statistical analyses were performed using the one-way analysis of variance (ANOVA) to evaluate differences between treatments followed by the Tukey test used to check differences between mean values with SPSS version 17.0 (SPSS Inc., USA). $P<0.05$ was considered statistically significant.

\section{Results and Discussion}

\section{Proximate and mineral composition}

Compositional analysis of the iron-fortified chewing gums revealed significant differences for ash- and nitrogen-free extract but nonsignificant results were found for moisture, crude protein, and crude fat (Table 1). The highest ash content was found in $\mathrm{T}_{3}(2.60 \pm 0.09 \%)$, followed by $\mathrm{T}_{4}(2.56 \pm 0.05 \%)$, while the lowest ash content was found in $\mathrm{T}_{2}(2.30 \pm 0.05 \%)$. The overall ash content of iron-fortified chewing gums was in the range of $2.30 \pm 0.05-2.60 \pm 0.09 \%$ whereas the ash content of non-fortified (control) chewing gums was $1.30 \pm 0.05 \%$. This increase in ash content was possibly due to the addition of fortificants. It was found in another study that the ash content of flour was increased with the fortification of iron from 1.63 to $1.76 \%$ (Akhtar et al., 2005). The highest nitrogen content was found in $\mathrm{T}_{2}(95.55 \pm$ $0.70 \%)$, followed by $\mathrm{T}_{4}(95.42 \pm 0.60 \%)$ whereas the lowest nitrogen content was found in $\mathrm{T}_{3}(95.12 \pm 0.10 \%)$. Overall, the nitrogen content of iron-fortified chewing gums was in the range of $95.12 \pm 0.1-95.55 \pm 0.70 \%$, while the nitrogen content of non-fortified (control) chewing gums was $96.64 \pm 0.90 \%$. Besides, mean values of moisture, protein, fiber, and fat were found in the range of $1.3 \pm 0.26-1.4 \pm 0.17 \%, 0.33 \pm 0.12-0.60 \pm 0.22 \%, 0.01 \pm 0.05-$ $0.03 \pm 0.04 \%$, and $0.49 \pm 0.16-0.53 \pm 0.17 \%$, respectively, whereas mean values of moisture, protein, fiber, and fat of non-fortified chewing gums were $1.7 \pm 0.17,0.27 \pm 0.17$, $0.2 \pm 0.005$, and $0.60 \pm 0.21 \%$, respectively. A similar pattern of the contents was found in another study, where tomato-based candy was prepared using $40 \%$ sugar solution. The results found similarity with the findings of Manjula and Suneetha (2014), who investigated that crude fiber in a hard candy prepared from pumpkin juice ranged from 1.20 to $2.24 \%$.

Mean values for the iron content of iron-fortified chewing gums revealed significant results (Table 1). The highest iron content $\left(334.03 \mathrm{mg} / \mathrm{kg}\right.$ ) was found in $\mathrm{T}_{4}$, followed by $\mathrm{T}_{2}(333.36 \mathrm{mg} / \mathrm{kg})$ whereas the minimum iron content was found in $\mathrm{T}_{2}(330.43 \mathrm{mg} / \mathrm{kg})$. Current results showed similarities with the findings of Manjula and Suneetha (2014).

\section{Texture analysis}

Mean values for the hardness of iron-fortified chewing gums were nonsignificant among treatments $(P>0.05)$. Overall hardness content of iron-fortified chewing gums remained in the range of 36.27-39.59 (N) (Table 1). The texture of chewing gums was the same due to the addition of the same ingredient except for iron salt, which showed that addition of salt does not affect the texture. Textural values of chewing gums were comparable with that of tomato candy prepared from $40 \%$ sugar solution (Kamruzzaman et al., 2014).

\section{Energy value}

Mean values of energy of iron-fortified chewing gums revealed a significant difference among treatments $(P<$ 0.05 ) (Table 1). Mean values of iron-fortified chewing gums revealed that the highest energy value was found in $\mathrm{T}_{3}(326.0 \mathrm{kcal} / 100 \mathrm{~g})$, followed by $\mathrm{T}_{2}(325.50 \mathrm{kcal} / 100 \mathrm{~g})$. The lowest energy was found in $\mathrm{T}_{4}(324.63 \mathrm{kcal} / 100 \mathrm{~g})$. The overall energy of iron-fortified chewing gums was in the range of $324.63-326.0 \mathrm{kcal} / 100 \mathrm{~g}$. $\mathrm{T}_{1}$ had less energy value, probably because of missing iron salt whereas other treatments have differences because of salt characteristics.

\section{Sensory evaluation}

Sensory evaluation of iron-fortified chewing gums revealed significant difference in flavor, mouthfeel, 
Table 1. Mean values for the effect of treatments on physiochemical characteristics of iron-fortified chewing gums.

\begin{tabular}{|c|c|c|c|c|c|c|c|c|c|}
\hline Treatment & $\begin{array}{c}\text { Moisture } \\
(\%)\end{array}$ & $\begin{array}{c}\text { Crude } \\
\text { protein } \\
(\%)\end{array}$ & $\begin{array}{c}\text { Crude } \\
\text { fiber } \\
(\%)\end{array}$ & $\begin{array}{c}\text { Crude fat } \\
(\%)\end{array}$ & $\begin{array}{l}\text { Ash } \\
(\%)\end{array}$ & $\begin{array}{l}\text { NFE } \\
(\%)\end{array}$ & $\begin{array}{c}\text { Energy } \\
\text { (kcal/100 g) }\end{array}$ & $\begin{array}{c}\mathrm{Fe} \\
(\mathrm{mg} / \mathrm{kg})\end{array}$ & $\begin{array}{c}\text { Texture } \\
\text { (N) }\end{array}$ \\
\hline $\mathrm{T}_{1}$ & $1.7 \pm 0.17$ & $0.267 \pm 0.17$ & $0.02 \pm 0.05$ & $0.60 \pm 0.21$ & $1.30 \pm 0.05^{d}$ & $96.64 \pm 0.9^{a}$ & $322.14 \pm 3.26^{d}$ & $0.01+0.25^{d}$ & $38.40 \pm 0.81$ \\
\hline $\mathrm{T}_{2}$ & $1.3 \pm 0.26$ & $0.43 \pm 0.17$ & $0.01 \pm 0.05$ & $0.53 \pm 0.17$ & $2.30 \pm 0.05^{c}$ & $95.55 \pm 0.7^{b}$ & $325.50 \pm 1.35^{b}$ & $330.43+0.24^{c}$ & $39.59 \pm 0.12$ \\
\hline $\mathrm{T}_{3}$ & $1.3 \pm 0.12$ & $0.60 \pm 0.22$ & $0.02 \pm 0.02$ & $0.50 \pm 0.12$ & $2.60 \pm 0.09^{a}$ & $95.12 \pm 0.1^{d}$ & $326.0 \pm 2.73^{a}$ & $333.36+0.17^{b}$ & $37.91 \pm 0.68$ \\
\hline $\mathrm{T}_{4}$ & $1.4 \pm 0.17$ & $0.33 \pm 0.12$ & $0.03 \pm 0.04$ & $0.49 \pm 0.16$ & $2.56 \pm 0.05^{b}$ & $95.42 \pm 0.6^{c}$ & $324.63 \pm 4.44^{c}$ & $334.03+0.13^{a}$ & $36.27 \pm 0.45$ \\
\hline
\end{tabular}

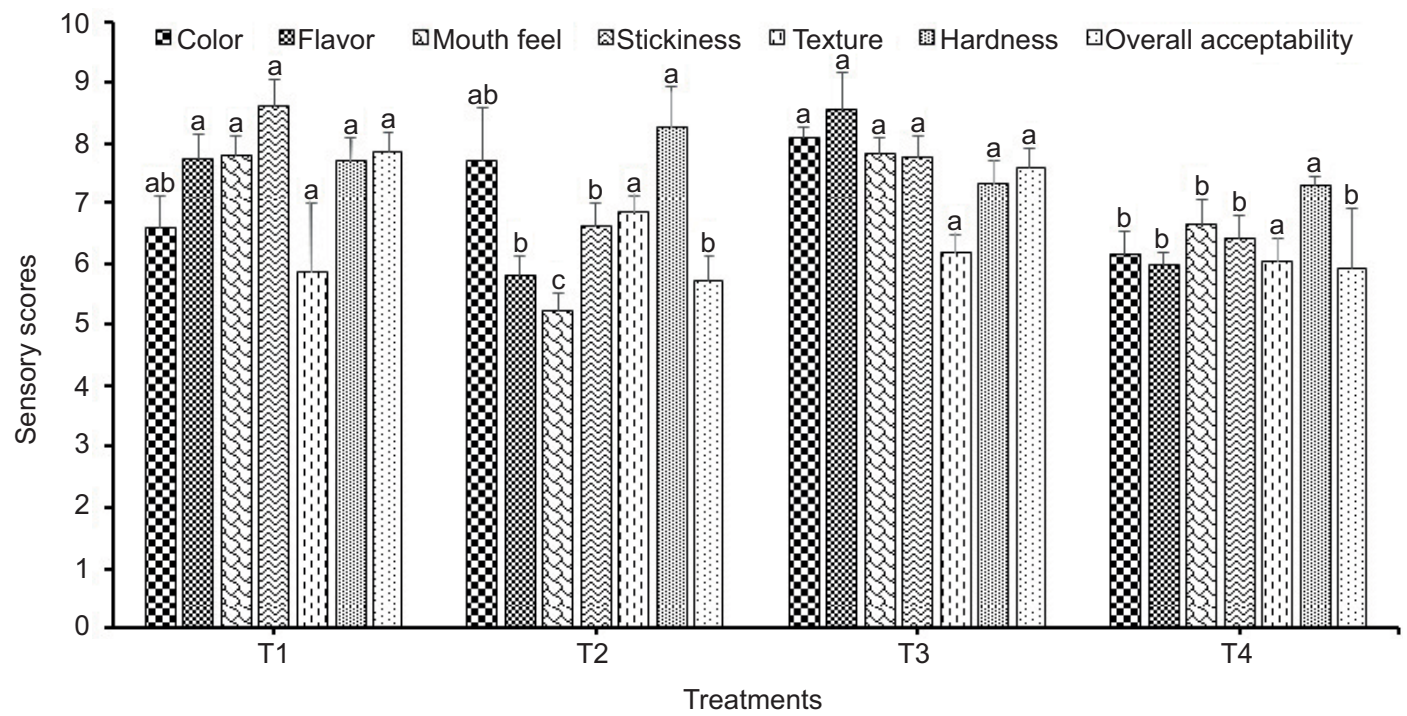

Figure 1. Sensory profile of $\mathrm{FeSO}_{4}$ - and NaFeEDTA-fortified chewing gums. Different letters on the same respective parameter bar indicate significant differences between mean values $(P<0.05)$.

stickiness, and overall acceptability but nonsignificant difference for color, texture, and hardness (Figure 1). The best flavor was found in $\mathrm{T}_{3}(8.54 \pm 0.62)$, followed by $\mathrm{T}_{4}$ $(5.99 \pm 0.19)$ whereas the lowest acceptable flavor was observed in $\mathrm{T}_{2}(5.81 \pm 0.31)$. The flavor of non-fortified (control) chewing gums was $7.74 \pm 0.40 . \mathrm{T}_{3}(7.84 \pm 0.26)$ secured the highest scores for mouthfeel, followed by $\mathrm{T}_{4}(6.63 \pm 0.41)$ whereas the lowest scores for the stated trait was found in $\mathrm{T}_{2}(5.23 \pm 0.29)$. The score for mouthfeel of non-fortified (control) chewing gums was $7.79 \pm$ 0.33 . The highest stickiness was found in $\mathrm{T}_{3}(7.76 \pm 0.37)$, trailed by $\mathrm{T}_{2}(6.61 \pm 0.38)$; however, the lowest stickiness was found in $\mathrm{T}_{4}(6.40 \pm 0.39)$. The stickiness of non-fortified (control) chewing gums was $8.62 \pm 0.42$. The highest overall acceptability was found for $\mathrm{T}_{3}(7.61 \pm 0.30)$, followed by $\mathrm{T}_{4}(5.91 \pm 0.98)$, while the lowest overall acceptability was shown by $\mathrm{T}_{2}(5.72 \pm 0.41)$. However, the score of overall acceptability of non-fortified (control) chewing gums was $7.87 \pm 0.30$. Mean values for color and hardness were found in the range of $6.59 \pm 0.55-8.10 \pm 0.16$ and $7.31 \pm 0.39-8.27 \pm 0.42$, respectively, while mean values for color and hardness of non-fortified chewing gums were $6.59 \pm 0.55$ and $7.71 \pm 0.39$, respectively. The highest sensory scores for texture was found in $\mathrm{T}_{2}(6.86 \pm 0.28)$, followed by $\mathrm{T}_{3}(6.19 \pm 0.25)$, while the lowest value was found in $\mathrm{T}_{4}(6.03 \pm 0.39)$. The score for texture of nonfortified (control) chewing gums was $5.87 \pm 1.12$. Indeed, the overall acceptability of food products was affected by fortificant types (Chadare et al., 2019; Davidsson et al., 2005). Current outcomes were consistent with the findings of Durrani et al. (2011), who elucidated the color scores of honey-based candy as 7.56-9.23. The flavor's sensory scores reported in the previous study on the quality evaluation of aonla (amla) candy prepared from steep preserved fruits ranged from 6-8\%, which were in agreement with the recent findings. The mouthfeel scores in the present study ranged from 5-6\%, which showed similarities to the scores reported by Bhattacherjee et al. (2013). The maximum score was given to $T_{3}$ because of the combination of $\mathrm{FeSO}_{4}$ and NaFeEDTA, as NaFeEDTA 
has the capability to mask the off-flavor produced by $\mathrm{FeSO}_{4}$. The lowest score was given to $\mathrm{T}_{2}$ because of bitter aftertaste imparted by $\mathrm{FeSO}_{4}$.

\section{Efficacy study}

\section{Hemoglobin}

Hemoglobin level was found significantly increased among the children fed with fortified chewing gums (Figure 2). Maximum increase in hemoglobin (3.22\%) was observed in children consuming chewing gums fortified with $100 \%$ NaFeEDTA, which ranged from 11.05 to $11.80 \mathrm{~g} / \mathrm{dL}$ (Table 2) whereas an increase in control group was $0.96 \%$ during the study trial of 45 days. Minimum increase $(2.31 \%)$ was noted in children fed with $100 \%$ $\mathrm{FeSO}_{4}$-fortified chewing gums. Overall, a significant improvement in the hemoglobin level of subjects was observed during the study period. It is concluded from the present exploration that the consumption of iron-fortified chewing gums is helpful to increase blood hemoglobin levels in school-going children. This increase was due to iron fortification, which is the basic component
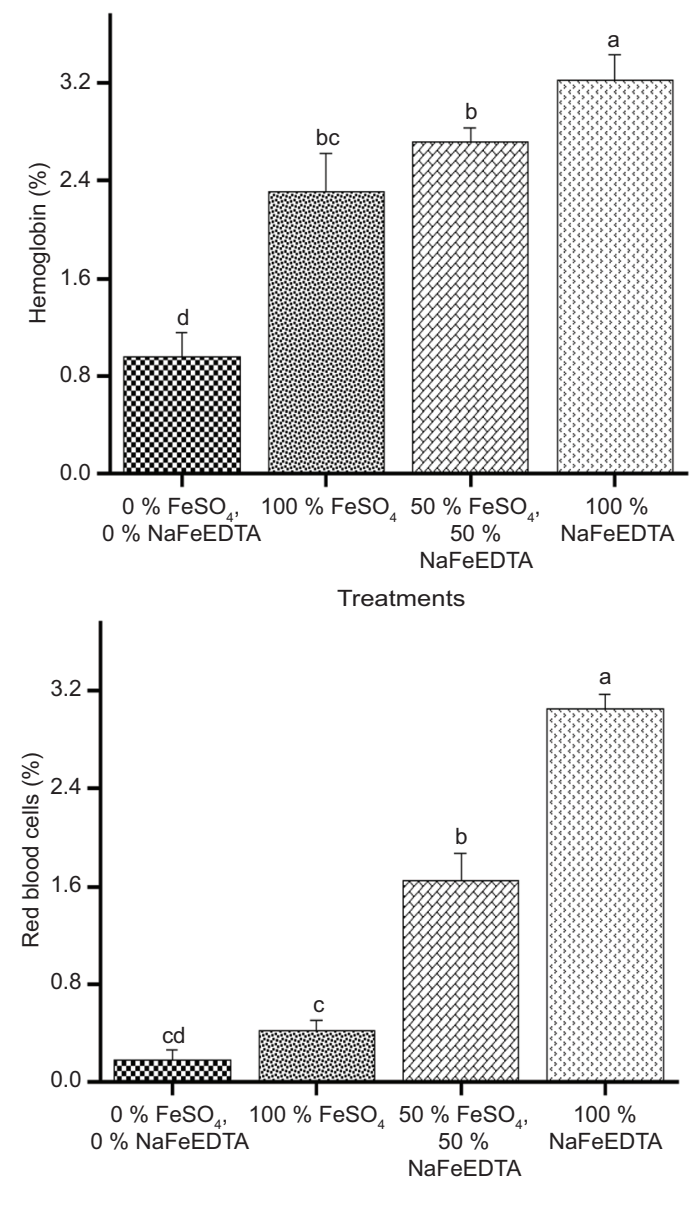

Treatments of hemoglobin, so an increase in iron in diet is directly related to the serum hemoglobin level (Longfils et al., 2008).

\section{Hematocrit}

Hematocrit percentage in school-going children revealed a significant increase after the consumption of iron-fortified chewing gums (Figure 2). This fortification induced improvement in hematocrit by up to $3.42 \%$ in children consuming chewing gums fortified with $100 \%$ NaFeEDTA that range from 35.92 to $38.12 \%$ as compared to the control group (0.98\%). The least increase (1.03\%) was found in the diet group fed with $100 \% \mathrm{FeSO}_{4}$-fortified chewing gums. It is concluded that iron-fortified chewing gums are helpful to increase hematocrit percentage in the blood. The results of hematocrit are related to the findings of hemoglobin. In another study, fortification was done using the micro-capsulated iron pyrophosphate $(500 \mathrm{~mL} / \mathrm{d})$ providing $18 \mathrm{mg}$ of iron in fruit juice and the influence was determined in menstruated women for eight weeks. Finding indicated that after the intervention, hematocrit increased by $3 \%$ as compared to control (Blanco-Rojo et al., 2011). Similarly, in another study
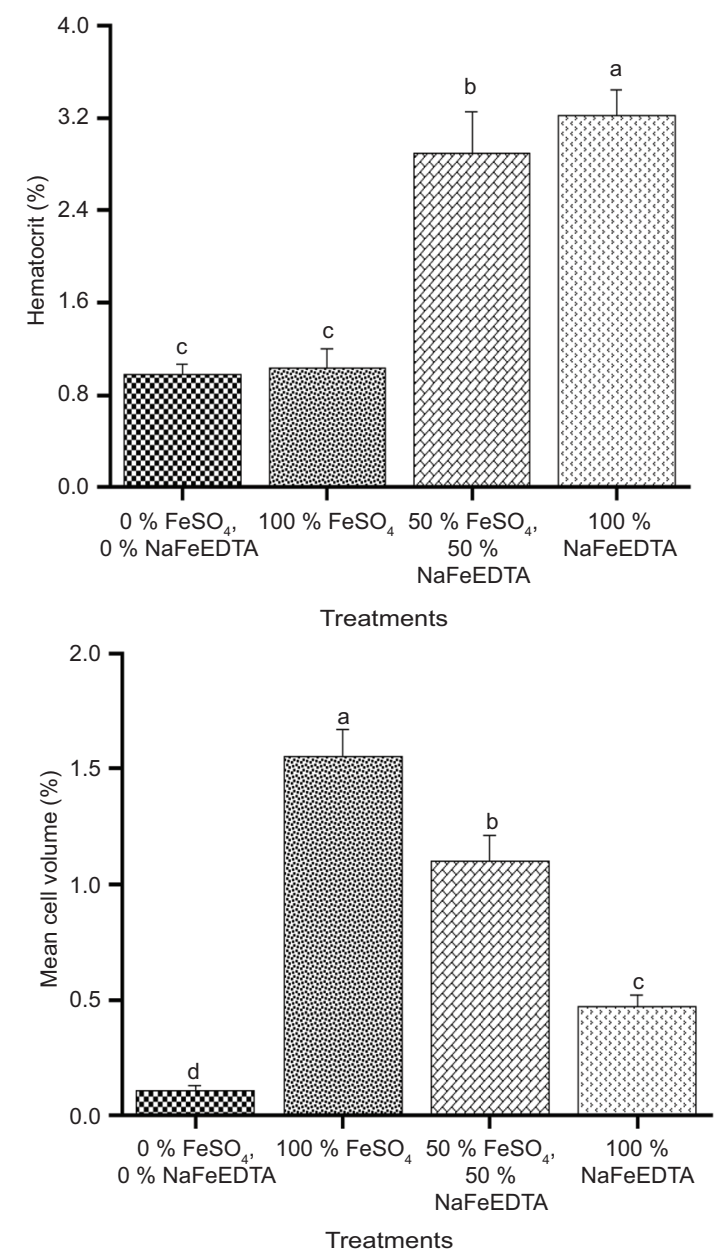

Figure 2. Percentage of hemoglobin, hematocrit, red blood cells, and mean cell volume deviation in school-going children influenced by the consumption of $\mathrm{FeSO}_{4}$ - and $\mathrm{NaFeEDTA}$-fortified chewing gums. 
hematocrit increased by $2 \%$ as compared to control after consumption of iron-fortified food (Patil et al., 2013).

\section{Red blood cells}

Changes in red blood cell count in children who consumed iron-fortified chewing gums are shown in (Figure 2). This fortification induced the highest red blood cells (3.05\%) in children consuming chewing gums fortified with $100 \%$ NaFeEDTA, which increased from 4.12 to $4.38 \mathrm{M} / \mathrm{UI}$, followed by the control group $(0.18 \%)$. The lowest increase in red blood cells $(0.42 \%)$ was found in the group fed with $100 \% \mathrm{FeSO}_{4}$-fortified chewing gums. This increase in the levels of red blood cells is related to improvement in the levels of hemoglobin. In another study, the fortification was done using the micro-capsulated iron pyrophosphate $(500 \mathrm{~mL} / \mathrm{d})$ by providing $18 \mathrm{mg}$ of iron in fruit juice to menstruated women for four weeks. This resulted in increase of red blood cells by up to $2 \%$ as compared to the control group (Blanco-Rojo et al., 2011).

\section{Mean cell volume}

Deviation in percentage values of MCV in school-going children is described in Figure 2. This fortification induced the highest MCV (1.55\%) in children consuming chewing gums fortified with $100 \%$ NaFeEDTA that improved from 82.95 to 85.91 femtoliters (fL), followed by the control group $(0.11 \%)$. The lowest increase in MCV $(0.47 \%)$ was found in the diet group fed with $100 \% \mathrm{FeSO}_{4}$-fortified chewing gums. It is obvious from the present results that recent fortificants are effective in increasing the MCV. The results of MCV are directly related to hemoglobin because hemoglobin is an ironbased protein in red blood cells. In another study done in India, tolerability and cost of three iron fortificants, such as ferrous fumarate $(100 \mathrm{mg})$, ferrous biglycinate $(100 \mathrm{mg})$, and carbonyl iron $(100 \mathrm{mg})$, among pregnant women were determined for 60 days; MCV concentration increased by $0.60 \%$ as compared to the control group (Patil et al., 2013).

\section{Mean Cell Hemoglobin}

Percentage values of $\mathrm{MCH}$ in school-going children by the consumption of iron-fortified chewing gums are presented in Figure 3. This fortification induced the highest $\mathrm{MCH}(5.43 \%)$ in children consuming chewing gums fortified with $100 \%$ NaFeEDTA that range from 23.47 to 26.17 picograms (pg), followed by the control group (0.98\%) (Table 2). The lowest increase in $\mathrm{MCH}(0.98 \%)$ was found in the group fed with $100 \% \mathrm{FeSO}_{4}$-fortified chewing gums. The findings of $\mathrm{MCH}$ are related to the findings of hemoglobin.

\section{Total White Blood Cells Count}

Percentage changes in TWBCC by the consumption of iron-fortified chewing gums by school-going children are shown in Figure 3. This fortification induced the highest TWBCC (7.98\%) in children consuming chewing gums fortified with $50 \% \mathrm{FeSO}_{4}$ and $50 \% \mathrm{NaFeEDTA}$, followed by the control group (3.35\%). The lowest increase in TWBCC (6.90\%) was found in the diet group fed with $100 \%$ NaFeEDTA, followed by (6.90\%) chewing gums fortified with $100 \% \mathrm{FeSO}_{4}$. It is obvious from the present findings that the consumption of iron-fortified chewing gums may be helpful in increasing TWBCC.

\section{Platelet Count}

Percentage changes in platelet count by consumption of iron-fortified chewing gums by school-going children are presented in Figure 3. This fortification induced the highest platelet count (4.40\%) in children consuming chewing gums fortified with $100 \%$ NaFeEDTA that increased from 136.75 to 89.50 thousands per cubic milliliter (K/uL), followed by the control group (0.59\%) (Table 2$)$. The lowest increase in platelet count $(0.61 \%)$ was found in the diet group fed with $100 \% \mathrm{FeSO}_{4}$ followed by the diet group fed with $50 \% \mathrm{FeSO}_{4}$ and $50 \% \mathrm{NaFeEDTA}(2.3 \%)$. The results showed that fortificants were effective in increasing the platelet count in normal individuals. Furthermore, increase in platelet count is mainly done in the bone marrow and affected by alcohol, drugs, hepatitis, medication, and anemia. Current results are consistent with the finding of Kulnigg-Dabsch et al. (2012).

\section{Serum Ferritin}

The results of increase in serum ferritin in school-going children after consuming iron-fortified chewing gums are presented in Figure 3. This fortification induced the highest increase in serum ferritin (7.43\%) in children consuming chewing gums fortified with 50\% NaFeEDTA and $50 \% \mathrm{FeSO}_{4}$, followed by the control group (2.08\%) (Table 2). The lowest increase in serum ferritin (6.52\%) was found in the group fed with $100 \%$ NaFeEDTAfortified chewing gums, followed by $100 \% \mathrm{FeSO}_{4}$-fortified chewing gums (5.3\%). In another study, impact of different iron fortificants, such as NaFeEDTA $(60 \mathrm{mg} / \mathrm{kg}$ ) and $\mathrm{FeSO}_{4}(20 \mathrm{mg} / \mathrm{kg})$, in wheat were observed in anemic school children and concluded that concentration of serum ferritin increased significantly by $3 \%$ as compared to the control group (Huang et al., 2009).

\section{Iron}

Percentage of iron consumption changes with the consumption of iron-fortified chewing gums in normal school-going children as shown in Figure 4. This fortification induced the highest percentage of iron (29.82\%) in children consuming chewing gums fortified with $100 \%$ NaFeEDTA, followed by the control group (16.14\%). The minimum increase in iron $(23.47 \%)$ was found in the diet group fed with 50\% NaFeEDTA- and 50\% FeSO4-fortified chewing gums. It is clear from the result that ironfortified chewing gums may be supportive in children fed 

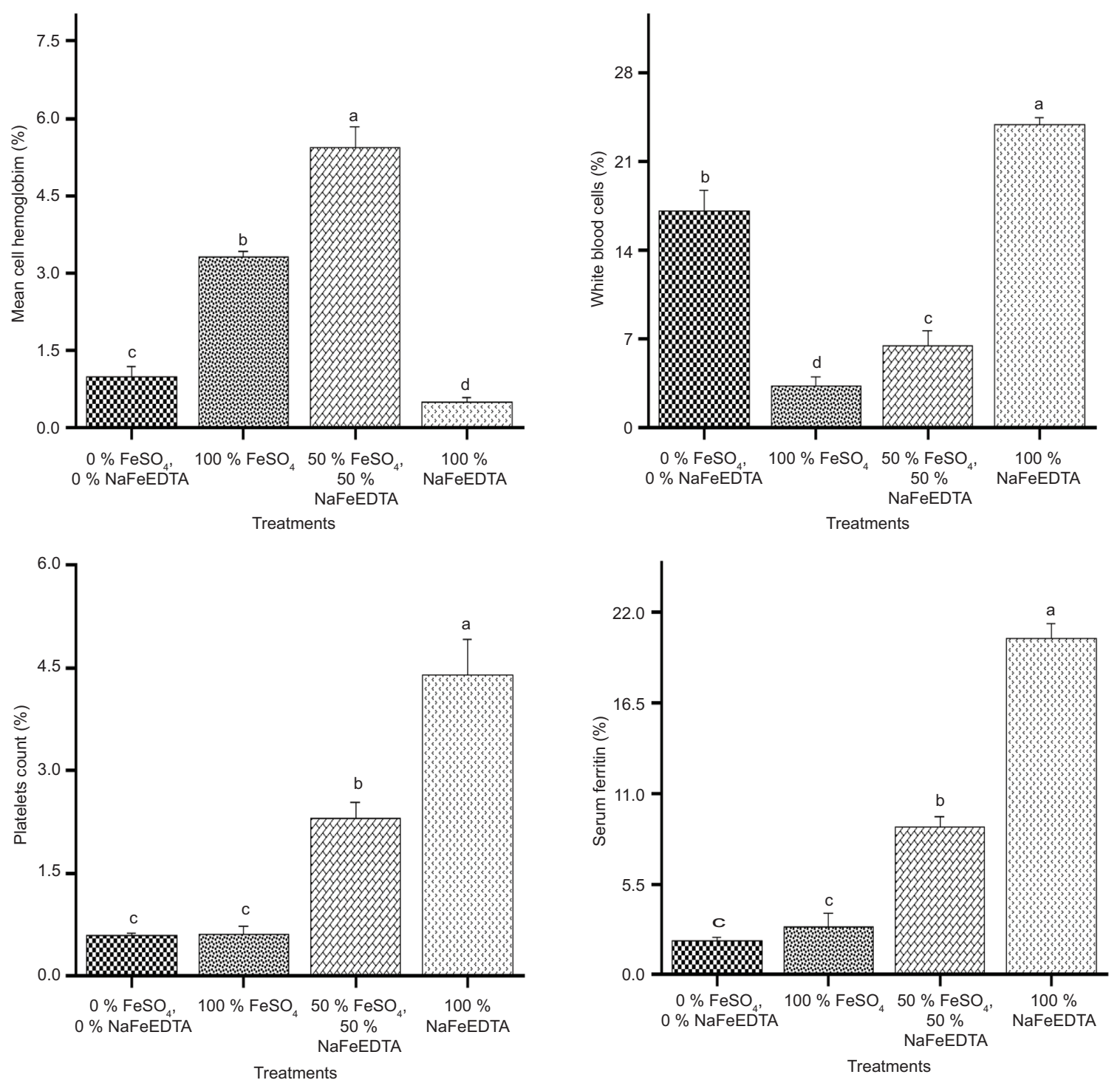

Figure 3. Percentage mean cell hemoglobin, total white blood cell count, platelets count, and serum ferritin deviation in school-going children affected by the consumption of $\mathrm{FeSO}_{4}$ - and NaFeEDTA-fortified chewing gums.

for enhancing iron consumption. The current findings were consistent with the findings of Ma et al. (2016).

\section{Conclusion}

Synthesized evidence revealed that consumption of iron-fortified chewing gums were found effective to improve hemoglobin, serum ferritin and iron status in school-going children aged of 6-10 years, and this is an inexpensive way to combat iron deficiency in lowto middle-income population. Chewing gums fortified with $\mathrm{FeSO}_{4}$ and NaFeEDTA (1:1) obtained highest sensory scores. Proximate composition and texture showed nonsignificant differences $(P>0.05)$, except ash, which might be due to the involvement of different iron salts. Conclusively, the findings of the current study infer that chewing gums fortified with $\mathrm{FeSO}_{4}$ and $\mathrm{NaFeEDTA}$ $(1: 1)$ possess significant potential to ensure nutritional security. The cost of chewing gums was calculated as PKR 2 per child per day. Diarrhea, widespread malabsorption, and enteropathy may be a barrier to this approach for the acquisition of maximum results. Further research in the future is needed to explain the mechanism underlying these outcomes along with rigorous randomized trials needed to resolve clinical and safety effectiveness.

\section{Acknowledgments}

The authors gratefully acknowledge the fund earmarked by the National Institute of Food Science \& Technology, University of Agriculture, Faisalabad, Pakistan. 
Table 2. Mean values of blood biochemical profile of school-going children.

\begin{tabular}{|c|c|c|c|c|c|c|c|c|}
\hline \multirow{2}{*}{$\begin{array}{l}\text { Treatments } \\
\text { Days }\end{array}$} & \multicolumn{2}{|c|}{$\mathrm{T}_{1}$} & \multicolumn{2}{|c|}{$\mathrm{T}_{2}$} & \multicolumn{2}{|c|}{$\mathrm{T}_{3}$} & \multicolumn{2}{|c|}{$\mathrm{T}_{4}$} \\
\hline & 0 & 45 & 0 & 45 & 0 & 45 & 0 & 45 \\
\hline $\mathrm{Hb}(\mathrm{g} / \mathrm{dL})$ & $11.25 \pm 0.32^{b}$ & $11.47 \pm 0.37^{\mathrm{a}}$ & $13.70 \pm 0.26^{b}$ & $14.35 \pm 1.74^{\mathrm{a}}$ & $11.65 \pm 0.26^{b}$ & $12.30 \pm 0.22^{\mathrm{a}}$ & $11.05 \pm 0.50^{b}$ & $11.80 \pm 0.35^{a}$ \\
\hline PCV (\%) & $34.32 \pm 1.55^{b}$ & $36.07 \pm 0.86^{a}$ & $42.85 \pm 2.04^{b}$ & $43.75 \pm 0.17^{\mathrm{a}}$ & $34.37 \pm 0.10^{b}$ & $36.42 \pm 1.44^{\mathrm{a}}$ & $35.72 \pm 0.74^{a}$ & $35.92 \pm 0.74^{a}$ \\
\hline RBC (M/uL) & $5.27 \pm 0.44^{a}$ & $5.29 \pm 0.53^{\mathrm{a}}$ & $4.70 \pm 0.15^{\mathrm{a}}$ & $4.66 \pm 0.08^{a}$ & $4.17 \pm 0.15^{b}$ & $4.31 \pm 0.13^{\mathrm{a}}$ & $4.12 \pm 0.35^{b}$ & $4.38 \pm 0.43^{\mathrm{a}}$ \\
\hline MCV (fL) & $90.40 \pm 1.0^{\mathrm{a}}$ & $90.20 \pm 0.80^{b}$ & $83.20 \pm 0.60^{b}$ & $84.0 \pm 0.30^{\mathrm{a}}$ & $71.50 \pm 0.90^{b}$ & $73.10 \pm 0.10^{a}$ & $82.95 \pm 0.50^{b}$ & $85.91 \pm 0.40^{\mathrm{a}}$ \\
\hline $\mathrm{MCH}(\mathrm{pg})$ & $26.87 \pm 0.88^{b}$ & $27.15 \pm 0.16^{a}$ & $29.75 \pm 0.78^{a}$ & $29.17 \pm 0.45^{b}$ & $27.15 \pm 0.49^{b}$ & $29.02 \pm 0.63^{\mathrm{a}}$ & $23.47 \pm 1.74^{b}$ & $26.17 \pm 0.10^{a}$ \\
\hline TWBC (K/uL) & $7.91 \pm 0.21^{b}$ & $8.46 \pm 0.31^{a}$ & $9.37 \pm 0.70^{b}$ & $10.70 \pm 0.11^{a}$ & $10.67 \pm 0.80^{b}$ & $12.52 \pm 0.87^{\mathrm{a}}$ & $7.62 \pm 0.70^{b}$ & $8.75 \pm 0.24^{\mathrm{a}}$ \\
\hline PLT (K/uL) & $280.17 \pm 1.80^{a}$ & $276.83 \pm 1.0^{b}$ & $286.10 \pm 1.10^{a}$ & $285.75 \pm 0.90^{b}$ & $260.75 \pm 0.71^{a}$ & $249.0 \pm 0.40^{b}$ & $136.75 \pm 0.79^{b}$ & $189.50 \pm 0.90^{a}$ \\
\hline $\mathrm{SF}(\mathrm{ng} / \mathrm{mL})$ & $21.30 \pm 0.15^{b}$ & $22.57 \pm 0.76^{a}$ & $25.45 \pm 0.90^{b}$ & $28.35 \pm 1.02^{\mathrm{a}}$ & $24.40 \pm 1.83^{b}$ & $28.32 \pm 0.73^{\mathrm{a}}$ & $28.95 \pm 0.34^{b}$ & $32.97 \pm 1.46^{\mathrm{a}}$ \\
\hline $\mathrm{ESR}(\mathrm{mm} / \mathrm{h})$ & $26.0 \pm 15.03^{b}$ & $28.17 \pm 22.04^{\mathrm{a}}$ & $9.15 \pm 4.12^{b}$ & $10.57 \pm 4.87^{a}$ & $12.5 \pm 4.15^{b}$ & $20.0 \pm 6.04^{\mathrm{a}}$ & $26.25 \pm 3.39^{b}$ & $51.42 \pm 7.41^{\mathrm{a}}$ \\
\hline $\mathrm{Fe}$ (ug/dL) & $88.8 \pm 44.94^{b}$ & $123.00 \pm 23.54^{a}$ & $60.85 \pm 19.24^{b}$ & $119.35 \pm 30.98^{a}$ & $51.75 \pm 17.71^{b}$ & $83.50 \pm 20.33^{a}$ & $53.92 \pm 16.94^{b}$ & $99.75 \pm 8.25^{a}$ \\
\hline
\end{tabular}

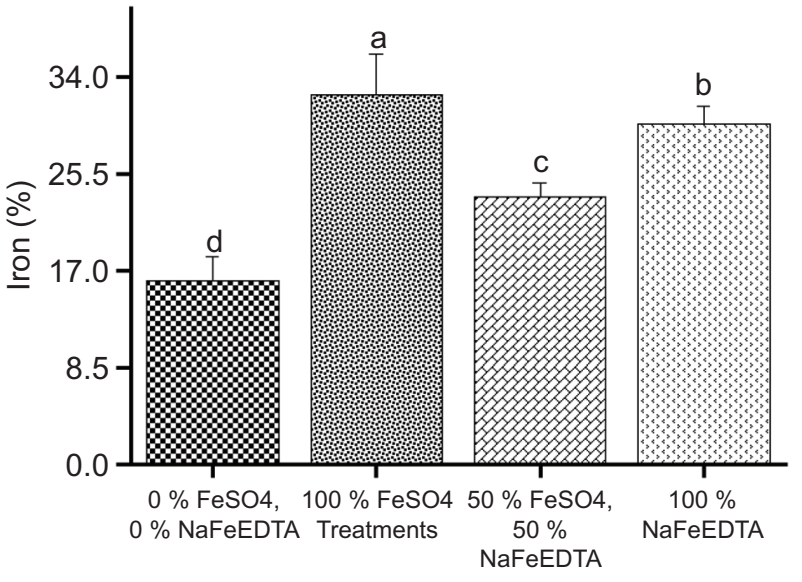

Figure 4. Percentage of iron deviation in school-going children affected by the consumption of $\mathrm{FeSO}_{4}$ - and $\mathrm{NaFeED}$ TA-fortified chewing gums.

\section{Conflict of Interest}

The authors declared no conflict of interest.

\section{References}

Akhtar S., Ahmed A., Ahmad A., Ali Z., Riaz M. and Ismail T. 2013. Iron status of the Pakistani population-current issues and strategies. Asia Pacific Journal of Clinical Nutrition 22:340-347.

Akhtar S., Anjum F.M. and Rehman S.U. 2005. Effect of iron and zinc fortification on the stability, acceptability and efficacy of whole wheat flour. Journal of Research 16:95-103.

Andang'o P.E., Osendarp S.J., Ayah R., West C.E., Mwaniki D.L., De Wolf C.A. and Verhoef H. 2007. Efficacy of iron-fortified whole maize flour on iron status of schoolchildren in Kenya: a randomised controlled trial. Lancet 369:1799-1806. https://doi. org/10.1016/S0140-6736(07)60817-4

Arcanjo F.P.N., Amancio O.M.S., Braga J.A.P. and de Paula Teixeira Pinto V. 2010. Randomized controlled trial of iron-fortified drinking water in preschool children. Journal of the American College of Nutrition 29:122-129. https://doi.org/10.1080/07315 724.2010.10719825

Azeem M., Mu T.H. and Zhang M. 2019. Effects of high hydrostatic pressure and soaking solution on proximate composition, polyphenols, anthocyanins, $\beta$-carotene, and antioxidant activity of white, orange, and purple fleshed sweet potato flour. Food Science and Technology International 0:1-15. https://doi. org/10.1177/1082013219892716

Bhattacherjee A.K., Dikshit A., Kumar S. and Tandon D.K. 2013. Quality of aonla candy and segments-in-syrup prepared from steep preserved fruits in water. Indian Journal of Natural Products and Resources 4:119-122.

Blanco-Rojo R., Pérez-Granados A.M., Toxqui L., GonzálezVizcayno C., Delgado M.A. and Vaquero M.P. 2011. Efficacy of a microencapsulated iron pyrophosphate-fortified fruit juice: a randomised, double-blind, placebo-controlled study in Spanish iron-deficient women. British Journal of Nutrition 105:16521659. https://doi.org/10.1017/S0007114510005490

Bouhouch R.R., El-Fadeli S., Andersson M., Aboussad A., Chabaa L., Zeder C. and Zimmermann M.B. 2016. Effects of wheat-flour biscuits fortified with iron and EDTA, alone and in combination, on blood lead concentration, iron status, and cognition in children: a double-blind randomized controlled trial1. American Journal of Clinical Nutrition 104:1318-1326. https://doi. org/10.3945/ajcn.115.129346

Chadare F.J., Idohou R., Nago E., Affonfere M., Agossadou J., Fassinou T.K and Hounhouigan D.J. 2019. Conventional and food-to-food fortification: an appraisal of past practices and 
lessons learned. Food Science \& Nutrition 7:2781-2795. https:// doi.org/10.1002/fsn3.1133

Davidsson L., Dimitriou T., Boy E., Walczyk T. and Hurrell R.F. 2002. Iron bioavailability from iron-fortified guatemalan meals based on corn tortillas and black bean paste. American Journal of Clinical Nutrition 75:535-539. https://doi.org/10.1093/ ajcn/75.3.535

Davidsson L., Ziegler E., Zeder C., Walczyk T. and Hurrell R. 2005. Sodium iron EDTA [NaFe(III)EDTA] as a food fortificant: erythrocyte incorporation of iron and apparent absorption of zinc, copper, calcium, and magnesium from a complementary food based on wheat and soy in healthy infants. American Journal of Clinical Nutrition 81:104-109. https://doi.org/10.1093/ ajcn/81.1.104

Durrani A.M., Srivastava P.K. and Verma S. 2011. Development and quality evaluation of honey-based carrot candy. Journal of Food Science and Technology 48:502-505. https://doi.org/10.1007/ s13197-010-0212-0

Huang J., Sun J., Li W.X., Wang L.J., Wang A.X., Huo J.S. and Chen C.M. 2009. Efficacy of different iron fortificants in wheat flour in controlling iron deficiency. Biomedical and Environmental Sciences 22:118-121. https://doi.org/10.1016/ S0895-3988(09)60033-7

Huo J., Sun J., Miao H., Yu B., Yang T., Liu Z. and Li Y. 2002. Therapeutic effects of NaFe EDTA-fortified soy sauce in anaemic children in China. Asia Pacific Journal of Clinical Nutrition 11:123-127. https://doi.org/10.104.6/j.1440-6047.2002.00277.x

Hurrell R. 2002. How to ensure adequate iron absorption from iron-fortified food. Nutrition Review 60:7-15. https://doi. org/10.1301/002966402320285137

Idris M. and Anis-ur-Rehman. 2005. Iron deficiency anaemia in moderate to severely anaemic patients. Journal of Ayub Medical College Abbottabad 17:45-47.

Kamruzzaman M., Islam M. and Anjuman S. 2014. A study on tomato candy prepared by dehydration technique using different sugar solutions. Food and Nutrition Sciences 5(13):1261-1271. https://doi.org/10.4236/fns.2014.513137

Khor G.L. 2005. Micronutrient status and intervention programs in Malaysia. Food and Nutrition Bulletin 26:281-285. https://doi. org/10.1177/15648265050262S220

Krishna G. and Ranjhan S.K. 1981. Gross energy of the herbage, urine, milk and silage. In: Laboratory manual of nutrition research. Vikas Publishing House (Pvt.) Ltd. New Delhi, India. pp.134.

Kulnigg-Dabsch S., Evstatiev R., Dejaco C. and Gasche C. 2012. Effect of iron therapy on platelet counts in patients with inflammatory bowel disease-associated anemia. PLoS ONE 7:1-6. https://doi.org/10.1371/journal.pone.0034520

Kuong K., Laillou A., Chea C., Chamnan C., Berger J. and Wieringa F.T. 2016. Stability of vitamin A, iron and zinc in fortified rice during storage and its impact on future national standards and programs-Case study in Cambodia. Nutrients 8:3-11. https://doi.org/10.3390/nu8010051

Longfils P., Monchy D., Weinheimer H., Chavasit V., Nakanishi Y. and Schumann K. 2008. A comparative intervention trial on fish sauce fortified with NaFe-EDTA and FeSO4+citrate in iron deficiency anemic school children in Kampot, Cambodia. Asia Pacific Journal of Clinical Nutrition 17:250-257.

Ma J., Sun Q., Liu J., Hu Y., Liu S., Zhang J. and Hambidge K.M. 2016. The effect of iron fortification on iron $(\mathrm{Fe})$ status and inflammation: a randomized controlled trial. PLoS ONE 11:112. https://doi.org/10.1371/journal.pone.0167458

Manjula K. and Suneetha C. 2014. Formulation and development of functional confectionery by incorporating pumpkin juice. International Journal of Food, Agriculture \& Veterinary Sciences 4:47-52.

McLean E., Cogswell M., Egli I., Wojdyla D. and De Benoist B. 2008. Worldwide prevalence of anaemia, WHO Vitamin and Mineral Nutrition Information System, 1993-2005. Public Health Nutrition 12:1-11. https://doi.org/10.1017/S1368980008002401

Meilgaard M.C., Civille G.V. and Carr B.T. 2007. Sensory evaluation techniques, 4th ed. CRC Press, New York, NY. https://doi. org/10.1201/b16452

Menon M.P. and Yoon S.S. 2015. Prevalence and factors associated with anemia among children under 5 years of age-Uganda, 2009. American Journal of Tropical Medicine and Hygiene 93:521-526. https://doi.org/10.4269/ajtmh.15-0102

Molla A. and Khurshid M. 1992. Prevalence of iron deficiency anaemia in children of the urban slums of Karachi. Journal Of Pakistan Medical Association 42:118-121.

Moretti D., Zimmermann M.B., Muthayya S., Thankachan P., Lee T.C., Kurpad A.V. and Hurrell R.F. 2006. Extruded rice fortified with micronized ground ferric pyrophosphate reduces iron deficiency in Indian schoolchildren: a double-blind randomized controlled trial1-3. American Journal of Clinical Nutrition 84:822-829. https://doi.org/10.1093/ajcn/84.4.822

Patil S., Khanwelkar C., Patil S.K. and Thorat V.M. 2013. Comparison of efficacy, tolerability, and cost of newer with conventional oral iron preparation. Al Ameen Journal of Medical Sciences 6:29-33.

Petry N., Olofin I., Hurrell R.F., Boy E., Wirth J.P., Moursi M. and Rohner F. 2016. The proportion of anemia associated with iron deficiency in low, medium, and high human development index countries: a systematic analysis of national surveys. Nutrients 8:1-17. https://doi.org/10.3390/nu8110693

Prentice A.M., Mendoza Y.A., Pereira D., Cerami C., Wegmuller R., Constable A. and Spieldenner J. 2017. Dietary strategies for improving iron status: balancing safety and efficacy. Nutrition Review 75:49-60. https://doi.org/10.1093/nutrit/nuw055

Sari M., Bloem M.W., De Pee S., Schultink W.J. and Sastroamidjojo S. 2001. Effect of iron-fortified candies on the iron status of children aged 4-6 y in East Jakarta, Indonesia. American Journal of Clinical Nutrition 73:1034-1039. https://doi.org/10.1093/ ajcn/73.6.1034

Schoorl M.,Van der Gaag D. and Bartels P.C.M. 2012. Effects of iron supplementation on red blood cell hemoglobin content in pregnancy. Hematology Reports 4:91-94. https://doi.org/10.4081/ hr.2012.e24

Siddiqui I.A., Siddiqui N.A., Aziz J. and Omair A. 2007. Erythrocyte sedimentation rate in healthy first year medical students. Saudi Medical Journal 28:1819-1821.

World Health Organization (WHO). 2011. The global prevalence of anaemia in 2011. WHO Report, 48, WHO, Geneva, Switzerland. 